\title{
Measurement of acceleration while walking as an automated method for gait assessment in dairy cattle
}

\author{
N. Chapinal,,${ }^{\star 1}$ A. M. de Passillé,† M. Pastell, $¥ \S$ L. Hänninen,§\# L. Munksgaard, Il and J. Rushen† \\ *Animal Welfare Program, University of British Columbia, 2357 Main Mall, Vancouver, BC, V6T 1Z4, Canada \\ †Agriculture and Agri-Food Canada, PO Box 1000, 6947 Highway 7, Agassiz, BC, V9M 1A0, Canada \\ fDepartment of Agrotechnology, PO Box 28, FI-00014 University of Helsinki, Finland \\ $\S R$ Research Centre for Animal Welfare, PO Box 57, Fl-00014 University of Helsinki, Finland \\ \#Department of Production Animal Medicine, PO Box 57, FI-00014 University of Helsinki, Finland \\ IIFaculty of Agricultural Sciences, Aarhus University, PO Box 50, DK-8830 Tjele, Denmark
}

\section{ABSTRACT}

The aims were to determine whether measures of acceleration of the legs and back of dairy cows while they walk could help detect changes in gait or locomotion associated with lameness and differences in the walking surface. In 2 experiments, 12 or 24 multiparous dairy cows were fitted with five 3 -dimensional accelerometers, 1 attached to each leg and 1 to the back, and acceleration data were collected while cows walked in a straight line on concrete (experiment 1) or on both concrete and rubber (experiment 2). Cows were video-recorded while walking to assess overall gait, asymmetry of the steps, and walking speed. In experiment 1 , cows were selected to maximize the range of gait scores, whereas no clinically lame cows were enrolled in experiment 2 . For each accelerometer location, overall acceleration was calculated as the magnitude of the 3-dimensional acceleration vector and the variance of overall acceleration, as well as the asymmetry of variance of acceleration within the front and rear pair of legs. In experiment 1 , the asymmetry of variance of acceleration in the front and rear legs was positively correlated with overall gait and the visually assessed asymmetry of the steps $(r \geq 0.6)$. Walking speed was negatively correlated with the asymmetry of variance of the rear legs $(r=$ -0.8 ) and positively correlated with the acceleration and the variance of acceleration of each leg and back $(\mathrm{r} \geq 0.7)$. In experiment 2 , cows had lower gait scores [2.3 vs. 2.6 ; standard error of the difference (SED) $=$ 0.1 , measured on a 5-point scale] and lower scores for asymmetry of the steps (18.0 vs. 23.1; SED $=2.2$, measured on a continuous 100-unit scale) when they walked on rubber compared with concrete, and their walking speed increased (1.28 vs. $1.22 \mathrm{~m} / \mathrm{s} ;$ SED $=0.02)$. The acceleration of the front (1.67 vs. $1.72 g$; $\mathrm{SED}=0.02)$

\footnotetext{
Received September 30, 2010.

Accepted February 25, 2011.

${ }^{1}$ Corresponding author: nchapinal@yahoo.com
}

and rear $(1.62$ vs. $1.67 g$; SED $=0.02)$ legs and the variance of acceleration of the rear legs ( 0.88 vs. $0.94 \mathrm{~g}$; $\mathrm{SED}=0.03)$ were lower when cows walked on rubber compared with concrete. Despite the improvements in gait score that occurred when cows walked on rubber, the asymmetry of variance of acceleration of the front leg was higher (15.2 vs. $10.4 \%$; SED $=2.0)$. The difference in walking speed between concrete and rubber correlated with the difference in the mean acceleration and the difference in the variance of acceleration of the legs and back $(r \geq 0.6)$. Three-dimensional accelerometers seem to be a promising tool for lameness detection on farm and to study walking surfaces, especially when attached to a leg.

Key words: concrete, lameness, rubber, walking speed

\section{INTRODUCTION}

Lameness is prevalent in modern dairy herds (Espejo et al., 2006; Ito et al., 2010), but producers have difficulties detecting lame cows (Whay et al., 2003; Espejo et al., 2006). Therefore, a need exists for better detection methods. Traditionally, lameness assessment has relied on subjective methods of gait scoring, yet this method is difficult on large farms. Some other behavioral changes in lame cows besides changes in gait might be monitored automatically using new technologies. For instance, lame cows show an unequal distribution of weight between their legs and this can be detected using force-plates that measure ground reaction forces when cows walk (Rajkondawar et al., 2006) or the weight that cows place on each leg while standing (Pastell and Kujala, 2007; Rushen et al., 2007; Chapinal et al., 2010a).

Commercially available activity loggers and 3-dimensional accelerometers attached to the legs have been used to measure the time that cows spend standing or lying and have shown that lame cows usually have longer lying bouts and lie down longer daily (Chapinal et al., 2009; Ito et al., 2010) than nonlame cows. Three- 
dimensional accelerometers can detect alterations in gait while cows are walking (Tanida et al., 2008) and have been used to identify severely lame cows (Pastell et al., 2009). These automated measures of lameness have been assessed by correlating them with gait scores. Gait is affected by walking surfaces such that concrete flooring, more than rubber flooring, has been associated with inferior gait (Telezhenko and Bergsten, 2005; Rushen and de Passillé, 2006; Flower et al., 2007). Therefore, correlating differences in gait with differences in acceleration when cows walk on different surfaces could be used as an alternative method to assess 3-dimensional accelerometers.

The aims were to determine whether measures of acceleration of the legs and back of dairy cows while they walk could help detect changes in gait or locomotion that were associated with lameness (experiment 1) or differences in the walking surface (experiment 2).

\section{MATERIALS AND METHODS}

\section{Animals and Housing}

Lactating Holstein cows were housed in sand-bedded freestalls $(2.4 \mathrm{~m}$ long $\times 1.2 \mathrm{~m}$ wide $\times 0.4 \mathrm{~m}$ deep $)$ at the University of British Columbia's Dairy Education and Research Centre in Agassiz, Canada. Cows were housed in groups of 12 to 36 with at least 1 freestall per cow. Cows were fed a TMR diet twice daily, formulated to meet requirements for dairy cows (NRC, 2001). Water was freely available from self-filling troughs. Cows were milked in the parlor at approximately 0800 and $1700 \mathrm{~h}$ daily. The experimental protocol was approved by the Institutional Animal Care Committee, which is monitored by the Canadian Council on Animal Care.

\section{General Procedures and Measures}

Gait Score. Cows were scored by walking them down a designated passageway ( $13 \mathrm{~m}$ long $\times 1.3 \mathrm{~m}$ wide $)$ after the morning milking. A handler walked behind the cows encouraging them to walk in a consistent manner. Each cow was video-recorded at normal speed from the side with a color digital camera (Sony DCRSR100 HDD Handycam Camcorder, 30 frames/s; Sony Corporation, Park Ridge, NJ) placed from 8 to $15 \mathrm{~m}$ from the cow, which allowed recording at least 4 complete strides for each cow during each passage. An experienced observer used these videos to score cow gait using a 1-to-5 numerical rating score (NRS; where $1=$ perfect gait and $5=$ severely lame) as described by Flower and Weary (2006) and Chapinal et al. (2009), and which has been related to the presence of hoof lesions. If a cow exceeded the requirements of a particular score, but did not meet all the requirements of the next successive score, a half-integer score was allocated. A continuous 100-unit visual analog scale (VAS) was used to assess overall gait (overall VAS) and asymmetry of the steps, a gait component associated with lameness and hoof lesions (Flower and Weary, 2006; Chapinal et al., 2009). Two marks separated by $9.35 \mathrm{~m}$ were painted on the floor and walls of the same passageway. Using the same video recordings described above, walking speed was calculated as the time between when the nose of the cow was aligned with the starting and end mark.

Accelerometers. Each cow was fitted with five 3-dimensional accelerometers (Hobo Pendant G Acceleration Data Logger, Onset Computer Corp., Pocasset, MA), described in Moreau et al. (2009) and de Passillé et al. (2010). Accelerometers were fitted in pouches. One accelerometer was attached by means of a strap to the lateral side of each leg above the fetlock. The fifth accelerometer was glued to a belt that was fastened around the torso such that the accelerometer was positioned approximately $10 \mathrm{~cm}$ to the right of the dorsal midline, at the level of the 8th to 10th thoracic vertebrae. The accelerometer measured a range of $\pm 3.2 \mathrm{~g}$ with an accuracy of $0.075 \mathrm{~g}$ at $25^{\circ} \mathrm{C}$. The accelerometer was set to sample at $33.3 \mathrm{~Hz}$, which allows about $10 \mathrm{~min}$ of data collection. Acceleration data from each walking passage (time to pass between the 2 wall markers in the passageway) were selected from the accelerometers' output by matching the accelerometers' output with the video recordings. In this way, only acceleration data collected when cows were walking in a straight line were used for the analyses. Only passages in which cows walked at a steady pace were considered.

\section{Specific Experimental Procedures}

Experiment 1. Twelve lactating multiparous dairy cows (mean $\pm \mathrm{SD}$; parity $=4.3 \pm 2.7 ; \mathrm{DIM}=103 \pm$ $60 \mathrm{~d}$; daily milk production $=39 \pm 7 \mathrm{~kg}$ ) were selected, maximizing the range of gait scores (NRS range $=1.5$ to 4.5). Data were collected over 3 different days (3-4 cows/d). Cows were restrained in headlocks after the morning milking and fitted with the 5 accelerometers as described above. Immediately, cows were video-recorded walking down a nongrooved concrete passageway from 4 to 7 times. All cows had previously been habituated to the area by walking them down the passageway at least 4 times/d for $4 \mathrm{~d}$.

Experiment 2. Twenty-four lactating multiparous dairy cows (mean $\pm \mathrm{SD}$; parity $=3 \pm 1 ; \mathrm{DIM}=121$ $\pm 19 \mathrm{~d}$; daily milk production $=44 \pm 13 \mathrm{~kg}$ ) judged as not being severely lame (NRS $<4$ and no hoof lesions) were selected. Hooves were scored within 4 wk before and within $4 \mathrm{wk}$ after the experiment to ensure 
that cows did not have any hoof lesions. On 5 different days, 5 or 6 cows were restrained in headlocks after the morning milking and fitted with the 5 accelerometers, as described in experiment 1 . Immediately after, cows were video-recorded walking down 1 of 2 parallel passageways that were either nongrooved concrete or nongrooved concrete covered with rubber. The rubber covering used consisted of a bottom layer of revulcanized rubber mats $(1.9 \mathrm{~cm}$ thick each; Animat, Saint-Élie d'Orford, QC, Canada) and an upper layer of antislip rubber (0.6 cm thick each, \#125 2-ply; Cobelt Canada Inc., Saint-Laurent, QC, Canada), as described in Rushen and de Passillé (2006). The passageways had the same dimensions as in experiment 1 . The rubber covering was switched between the 2 passageways each day. Cows were walked from 6 to 8 times, alternating the passageways at each trial. The order of the treatments was balanced across cows. All cows had been previously habituated to the area by walking them down the passageway at least 4 times/d for $4 \mathrm{~d}$.

\section{Data and Statistical Analysis}

The raw acceleration data were summarized with $\mathrm{R}$ (version 2.80; R Development Core Team, 2008) and the statistical analysis was conducted using SAS (version 9.1; SAS Institute, 2003). From the acceleration data collected for each of the 3 axes from each of the 5 accelerometer locations, the overall acceleration was calculated as the magnitude of the 3-dimensional acceleration vector for each leg and for the back accelerometer as follows:

$$
\text { Acceleration }(g)=\sqrt{a c c_{x}^{2}+a c c_{y}^{2}+a c c_{z}^{2}} \text {, }
$$

where $a c c_{x}$ is the acceleration along the $\mathrm{x}$-axis, $a c c_{y}$ is the acceleration along the y-axis, and $a c c_{z}$ is the acceleration along the z-axis. Similar results were obtained using the acceleration vector and the acceleration in each axis and therefore only the acceleration vector will be discussed. For each accelerometer location, the mean acceleration and the variance over time of acceleration were calculated based on this vector. To calculate the mean acceleration for each location, the acceleration was averaged over time to get a single mean value per passage, and then averaged across passages to get a single mean value per cow (and surface in experiment 2 ). Acceleration was averaged across each pair of contralateral legs to get 1 value for the front pair and 1 value for the rear pair of legs. For each accelerometer location, the variance of acceleration over time was calculated for each passage. The asymmetry of variance of acceleration was analyzed within each pair of legs as follows:

$$
\begin{gathered}
\text { Asymmetry of variance }(\%)= \\
{\left[1-\left(\text { Variance }_{\min } / \text { Variance }_{\max }\right)\right] \times 100,}
\end{gathered}
$$

where Variance $_{\min }$ is the variance of acceleration of the leg with least variance, and Variance $_{\max }$ is the variance of acceleration of the leg with largest variance. Values of variance for each accelerometer location, and asymmetry of variance of acceleration for each pair of legs were averaged across passages to get a value per cow (and surface in experiment 2). Variance was averaged across contralateral legs to get 1 value for the front legs and 1 value for the rear legs.

Experiment 1. One to 4 passages/cow, in which cows were walking at a steady pace, were selected for the final analyses. Passages in which cows ran, stopped, or kept the head low were eliminated. Correlations (PROC CORR) were calculated between gait (NRS, overall VAS, and degree of asymmetry of the steps), walking speed, and the acceleration variables (mean acceleration of each leg and back, variance of acceleration of each leg and back, and asymmetry of variance of acceleration of the front and rear legs). Pearson correlation coefficients were calculated in all cases except for the correlations between NRS and the other variables, in which cases Spearman correlations were calculated. Results were very similar when the mean acceleration and the variance of acceleration of each leg were considered individually and when the values for each pair of legs (front and back) were averaged; therefore, only correlation coefficients based on averages are presented.

Experiment 2. One to 4 passages/cow per surface were selected following the same criteria as in experiment 1. A mixed model (PROC MIXED) that included day of test as a random block factor, surface as a fixed effect, and cow as a random effect was used to test differences in NRS, overall VAS, asymmetry of the steps, and walking speed in response to the different walking surfaces. A similar model that included walking speed as a covariate and the interaction between walking speed and surface was used to analyze differences in the acceleration variables. Residuals were examined to verify normality and homogeneity of variances after each model. Numerical rating score was an ordinal variable, but because it included a large number of response categories and assumptions of normality and homogeneity of variances were met, it was treated as an interval-dependent variable in all analyses (ChuangStein and Agresti, 1997). The differences found in NRS were confirmed by differences in the continuous vari- 
able overall VAS, which was correlated to NRS ( $\mathrm{r}=$ 0.99; $P<0.001)$.

For each cow, the difference between the mean value of each variable when cows walked on concrete and rubber was calculated by subtracting the values for rubber from the values for concrete, and the difference between surfaces in gait and walking speed was correlated to the difference between surfaces in acceleration measures (PROC CORR).

\section{RESULTS}

\section{Experiment 1}

The mean acceleration and variance of acceleration were not correlated with gait measures in any accelerometer location, whereas the asymmetry of variance of acceleration in the front and rear legs was positively correlated with NRS, overall VAS, and asymmetry of the steps (Table 1; Figure 1). Walking speed was positively correlated with the mean acceleration and variance of acceleration measured on the back and each leg (both when legs were considered individually and when values for each pair of legs were averaged) and negatively correlated to the asymmetry of variance of the rear legs (Figure 2). Walking speed was negatively correlated with asymmetry of the steps $(\mathrm{r}=-0.63 ; P$ $=0.03)$, but not with NRS or overall VAS.

\section{Experiment 2}

Cows had lower gait scores (NRS and overall VAS) and scores for asymmetry of the steps when they walked on rubber compared with concrete, and their walking speed increased (Table 2). The mean acceleration of
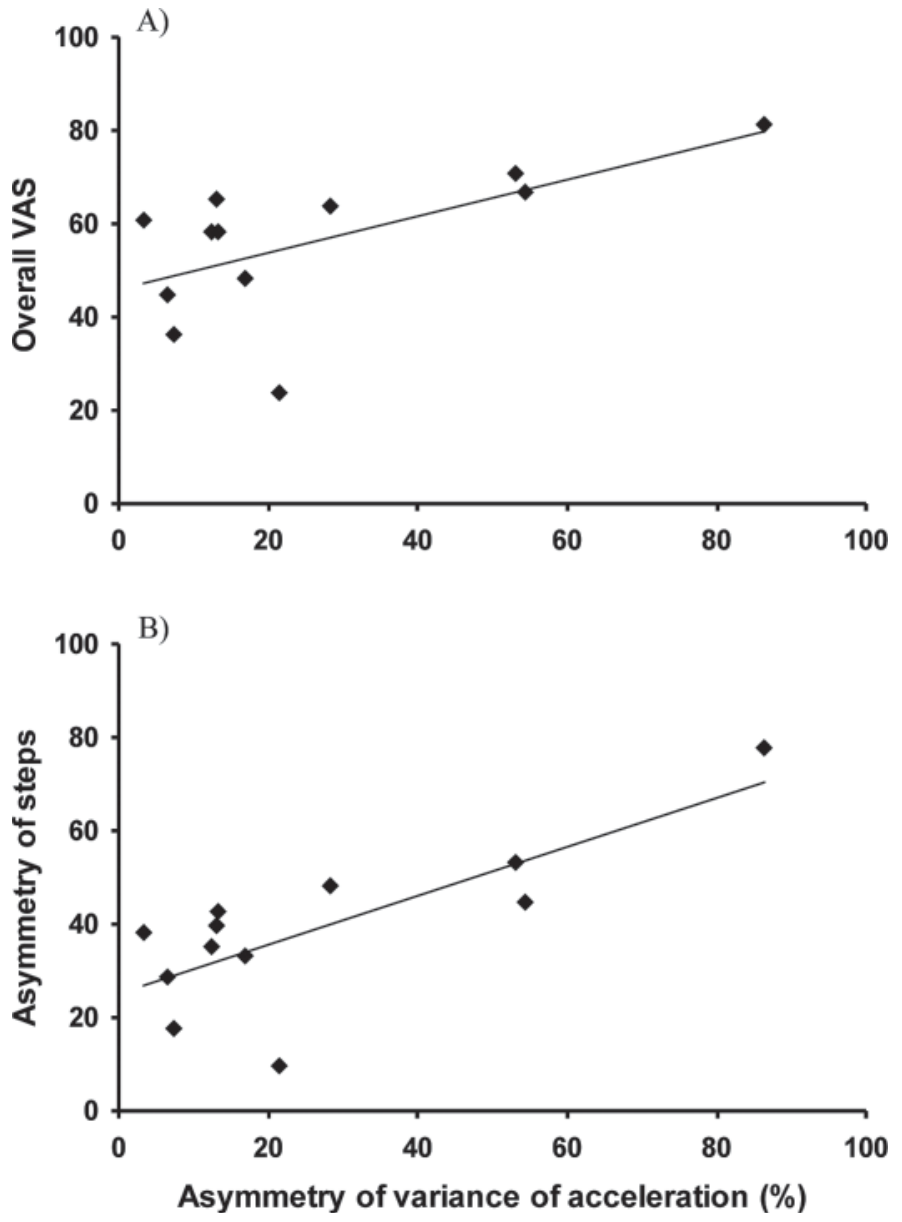

Figure 1. Relationship between the asymmetry of variance of acceleration of the rear legs and overall gait scored on a continuous 100-unit visual analog scale (VAS; A; $\mathrm{r}=0.63$ ) and visually assessed asymmetry of the steps $(\mathrm{B} ; \mathrm{r}=0.77)$ for 12 multiparous cows while walking in a straight line on concrete.

Table 1. Correlations between measures of gait and walking speed, and measures of acceleration for 12 multiparous cows with numerical rating score (NRS) ranging from 1.5 to 4.5 while walking in a straight line on concrete

\begin{tabular}{lcccc}
\hline Acceleration variable & NRS & $\begin{array}{c}\text { Overall } \\
\text { VAS }^{2}\end{array}$ & $\begin{array}{c}\text { Asymmetry } \\
\text { of the steps }\end{array}$ & $\begin{array}{c}\text { Walking } \\
\text { speed }^{3}(\mathrm{~m} / \mathrm{s})\end{array}$ \\
\hline Front legs mean acceleration $(g)$ & -0.08 & -0.03 & -0.29 & $0.84^{* * *}$ \\
Rear legs mean acceleration $(g)$ & -0.26 & -0.23 & -0.46 & $0.90^{* * *}$ \\
Variance of front legs acceleration & 0.04 & -0.28 & 0.09 & $0.74^{* *}$ \\
Variance of rear legs acceleration & -0.15 & -0.37 & -0.12 & $0.87^{* * *}$ \\
Front legs asymmetry of variance $(\%)$ & $0.71^{*}$ & $0.68^{*}$ & $0.75^{* *}$ & -0.56 \\
Rear legs asymmetry of variance $(\%)$ & $0.60^{*}$ & $0.63^{*}$ & $0.77^{* *}$ & $-0.76^{* *}$ \\
Back mean acceleration $(g)$ & -0.12 & -0.13 & -0.24 & $0.69^{*}$ \\
Variance of back acceleration & -0.30 & -0.37 & -0.18 & $0.78^{* *}$ \\
\hline
\end{tabular}

${ }^{1}$ Scored on a 5-point scale with half-integer scores. Spearman correlation coefficient.

${ }^{2}$ Overall gait, scored on a continuous 100-unit visual analog scale.

${ }^{3}$ Scored on continuous 100-unit visual analog scales.

${ }^{4}$ Pearson correlation coefficient.

${ }^{* * *} P<0.001 ;{ }^{* *} P<0.01 ;{ }^{*} P<0.05$. 

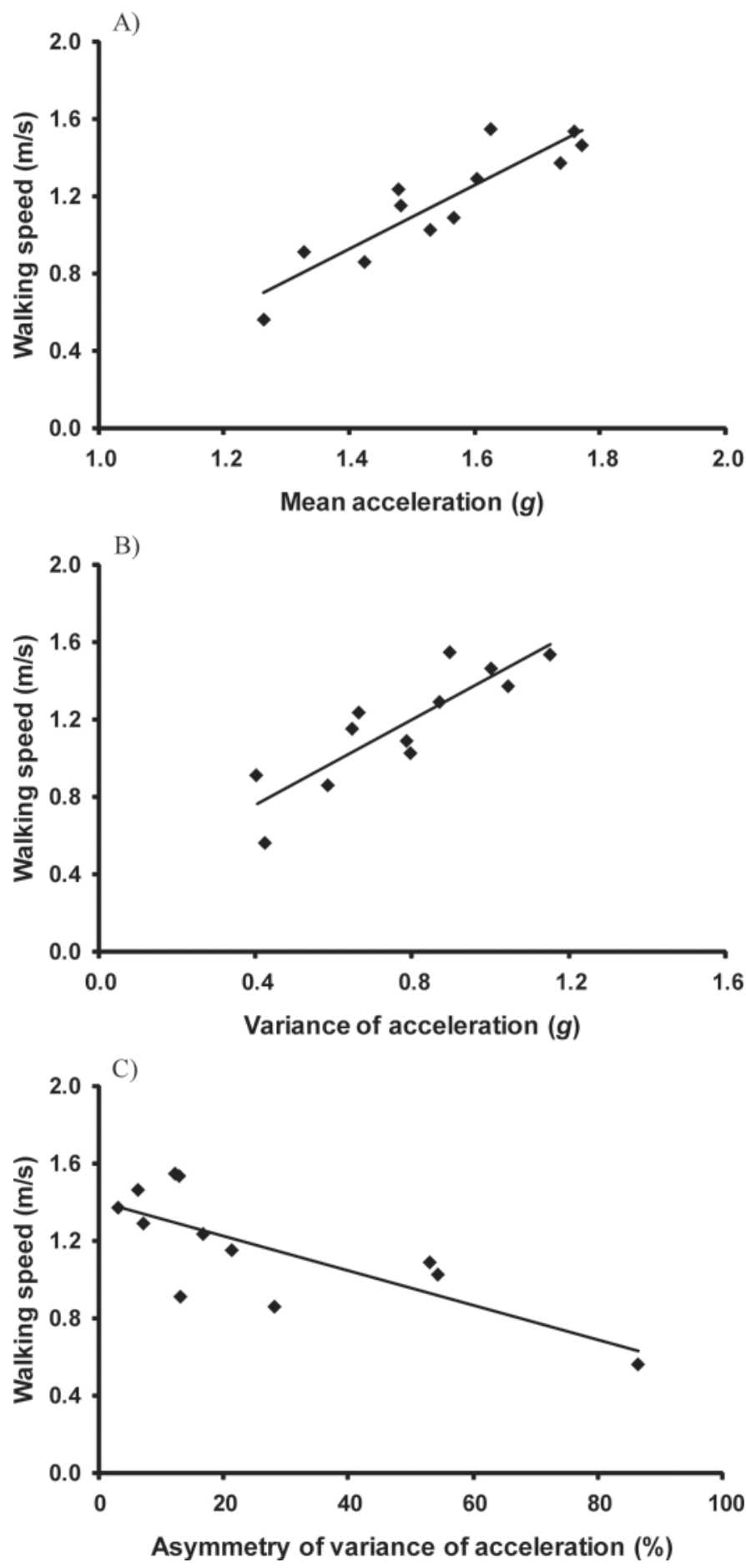

Figure 2. Relationship between walking speed and mean overall acceleration $(\mathrm{A} ; \mathrm{r}=0.90)$, variance of acceleration $(\mathrm{B} ; \mathrm{r}=0.87)$, and asymmetry of variance of acceleration $(\mathrm{C} ; \mathrm{r}=-0.76)$ recorded in the rear legs of 12 multiparous cows while walking in a straight line on concrete. the front and rear legs and the variance of acceleration of the rear legs were lower when the cows walked on rubber compared with concrete, after including walking speed as a covariate in the model. Despite the improvements in gait score that occurred when cows walked on rubber, the asymmetry of variance of acceleration of the front leg was higher. Walking speed as a covariate showed a positive relationship with mean acceleration and the variance of acceleration of the front legs, rear legs, and back $(P<0.01$ in all cases $)$.

The difference in walking speed between concrete and rubber was related to differences in several measures of acceleration. The difference in walking speed between concrete and rubber correlated with the difference in the mean acceleration of the front legs $(\mathrm{r}=0.64 ; P=$ $0.001)$, the rear legs $(\mathrm{r}=0.71 ; P<0.001)$, and the back $(\mathrm{r}=0.61 ; P=0.01)$, and with the difference in the variance of acceleration of the front legs $(\mathrm{r}=0.69$; $P<0.001)$, the rear legs $(\mathrm{r}=0.71 ; P<0.001)$, and the back $(\mathrm{r}=0.59 ; P=0.003)$. The difference in walking speed did not correlate with the difference in the asymmetry of variance of acceleration of the front and rear legs. Differences in gait and asymmetry of the steps did not correlate to the difference in any of the acceleration measures $(P>0.15)$.

\section{DISCUSSION}

Experiment 1 showed that asymmetry of variance of acceleration measured in both the front and rear pair of legs was correlated with gait scores, particularly with the asymmetry of the steps, which is the main change in gait that occurs when animals become lame (Chapinal et al., 2009). That is, lame cows with high gait scores had a greater asymmetry of variance of acceleration in the front and rear pairs of legs. Several studies that measured the weight that cows place on each leg when walking or standing showed that lame cows try to reduce the load on the affected leg (Rajkondawar et al., 2006; Rushen et al., 2007; Chapinal et al., 2010b); as a result, gait is impaired and steps are asymmetrical (Flower et al., 2005; Flower and Weary, 2006; Chapinal et al., 2009). Furthermore, the asymmetries in the steps observed when cows walk have been quantified using kinematic measures (Flower et al., 2005) and measurements from footprints (trackway measurement system; Telezhenko and Bergsten, 2005). Pastell et al. (2009) found that cows with altered gait showed a greater asymmetry of variance of the forward acceleration, but only in the case of the rear legs. Asymmetries between contralateral legs seem to be good predictors of lameness and this can be assessed by observing cows walking or by using different automated methods. 
Table 2. Least squares means and standard error of the difference (SED) for measures of gait, walking speed, and acceleration for 24 multiparous cows while walking in a straight line on concrete or rubber flooring; walking speed was included as a covariate in the acceleration measures' models

\begin{tabular}{|c|c|c|c|c|}
\hline Variable & Concrete & Rubber & SED & $P$-value \\
\hline $\mathrm{NRS}^{1}$ & 2.6 & 2.3 & 0.1 & $<0.001$ \\
\hline Overall VAS ${ }^{2}$ & 43.2 & 38.9 & 1.4 & 0.01 \\
\hline Asymmetry of the steps ${ }^{3}$ & 23.1 & 18.0 & 2.2 & 0.02 \\
\hline Walking speed $(\mathrm{m} / \mathrm{s})$ & 1.22 & 1.28 & 0.02 & 0.03 \\
\hline Front legs mean acceleration $(g)$ & 1.72 & 1.67 & 0.02 & 0.02 \\
\hline Rear legs mean acceleration $(g)$ & 1.67 & 1.62 & 0.02 & 0.01 \\
\hline Variance of front legs acceleration & 0.88 & 0.84 & 0.02 & 0.11 \\
\hline Variance of rear legs acceleration & 0.94 & 0.88 & 0.03 & 0.04 \\
\hline Front legs asymmetry of variance (\%) & 10.4 & 15.2 & 2.0 & 0.02 \\
\hline Rear legs asymmetry of variance (\%) & 13.5 & 14.0 & 2.0 & 0.81 \\
\hline Back mean acceleration $(g)$ & 0.99 & 0.99 & 0.002 & 0.76 \\
\hline Variance of back acceleration & 0.03 & 0.03 & 0.002 & 0.58 \\
\hline
\end{tabular}

${ }^{1}$ Numerical rating score on a 5-point scale with half-integer scores.

${ }^{2}$ Overall gait scored on a continuous 100-unit visual analog scale.

${ }^{3}$ Scored on continuous $100-$ unit visual analog scales.

Mean acceleration was a good predictor of walking speed, particularly when data were collected from any of the legs, and to a lesser extent, when data were collected by placing an accelerometer on the back of the cows. This finding is very promising, because Chapinal et al. (2010a) found that combining measures of walking speed with automated measures of lying time and weight distribution improved the identification of lame cows. In this study, no correlation was observed between walking speed and overall gait score, which may reflect the small sample size. However, walking speed was negatively correlated with asymmetry of the steps, which has been described as one of the gait components that best predicts cows with sole ulcers (Chapinal et al., 2009). One single accelerometer attached to $1 \mathrm{leg}$ appears to be a promising way to continuously monitor walking speed that could easily be applied on the farm.

In experiment 2, the effectiveness of the accelerometers in detecting changes in gait that occurred when cows walked on different flooring surfaces was examined. Gait was improved and walking speed was higher when cows walked on rubber compared with concrete, supporting previous research (Telezhenko and Bergsten, 2005; Rushen and de Passillé, 2006; Flower et al., 2007). After controlling for walking speed in the model, the mean acceleration of the front and rear legs and the variance of acceleration of the rear legs were higher on concrete. This is the first evidence to support earlier suggestions that rubber, compared with concrete, reduces acceleration on the legs. These results suggest that, at the same walking speed, gait is smoother when cows walk on rubber. Rubber absorbs some of the impact of the hoof, which likely affects acceleration. Reducing speed may be a strategy to reduce acceleration on concrete and thus the impact of the hooves when they hit the ground.
In experiment 1, a positive correlation was found between gait score and asymmetry of variance of acceleration. In contrast to our predictions, cows in experiment 2 showed a greater asymmetry of variance of acceleration of the front legs when walking on rubber even though they had lower gait scores. The asymmetry of variance of acceleration was low in this study because severely lame cows were avoided, and therefore, the difference might not be biologically relevant. The different anatomy and mechanical function of the front legs (steering vs. pushing; Phillips, 2002) may have contributed to this result. Research shows that asymmetry in the weight distribution of the rear legs is a better predictor of lameness than asymmetry in the weight distribution of the front legs (Chapinal et al., 2010a,b). The asymmetry of the steps when assessed visually is probably more easily identified on the rear legs than on the front. Therefore, further research is needed to understand whether a greater asymmetry of variance of acceleration in the front legs, rather than the rear legs, is related to lameness.

Changes in leg acceleration measures were positively correlated to changes in walking speed between surfaces. These results suggest that acceleration measures are sensitive enough to identify small changes in walking speed within cows. Although walking speed has been shown to be a good predictor of gait impairment (Chapinal et al., 2010a), further research is needed to validate the use of changes in walking speed within cows to detect lameness.

Chapinal et al. (2010a) concluded that a combination of different automated methods for lameness detection, such as weight distribution, lying behavior, and walking speed, could increase the accuracy in detecting lame cows, which is particularly interesting in large freestallhoused herds. Three-dimensional accelerometers are 
currently used on some commercial farms to monitor activity, particularly for heat detection and lying behavior. An improved version of a 3-dimensional accelerometer attached to 1 single leg could continuously monitor activity, lying behavior, and walking speed at the same time.

In conclusion, the asymmetry of variance of acceleration within a pair of legs was correlated to gait and visually assessed asymmetry of the steps. Measures of acceleration and its variance collected by 3 -dimensional accelerometers were correlated to walking speed, particularly when the accelerometer was attached to the legs, and to a lesser extent, when attached to the back of the cows. Accelerometers identified differences in acceleration when cows walked on concrete or rubber. Small differences in walking speed between surfaces were correlated to differences in acceleration measures. Three-dimensional accelerometers seem to be a promising tool for lameness detection on farm and to study walking surfaces, especially when attached to a leg. If accelerometers are to be used as a diagnostic tool, future larger scale studies are needed to assess the sensitivity and specificity of the measures under practical conditions.

\section{ACKNOWLEDGMENTS}

We thank Kate Kjelsrud, Alejandra Barrientos, and the staff and students at the University of British Columbia's Dairy Education and Research Centre (Agassiz, BC, Canada) for their help in running the experiments. The research was supported by the Natural Sciences and Engineering Research Council of Canada (Ottawa, ON), Dairy Farmers of Canada (Ottawa, ON), Global Animal Partnerships and Agriculture (Austin, TX), and Agri-Food Canada (Ottawa, ON).

\section{REFERENCES}

Chapinal, N., A. M. de Passillé, J. Rushen, and S. Wagner. 2010a. Automated methods for the detection of lameness and analgesia in dairy cattle. J. Dairy Sci. 93:2007-2013.

Chapinal, N., A. M. de Passillé, J. Rushen, and S. Wagner. 2010b. Effect of analgesia during hoof trimming on gait, weight distribution and activity of dairy cattle. J. Dairy Sci. 93:3039-3046.

Chapinal, N., A. M. de Passillé, D. M. Weary, M. A. G. von Keyserlingk, and J. Rushen. 2009. Using gait score, walking speed, and lying behavior to detect hoof lesions in dairy cows. J. Dairy Sci. 92:4365-4374.

Chuang-Stein, G., and A. Agresti. 1997. A review of tests for detecting a monotone dose-response relationship with ordinal response data. Stat. Med. 16:2599-2618.

de Passillé, A. M., M. B. Jensen, N. Chapinal, and J. Rushen. 2010. Technical note: Use of accelerometers to describe gait patterns in dairy calves. J. Dairy Sci. 93:3287-3293.

Espejo, L. A., M. I. Endres, and J. A. Salfer. 2006. Prevalence of lameness in high-producing Holstein cows housed in freestall barns in Minnesota. J. Dairy Sci. 89:3052-3058.

Flower, F. C., A. M. de Passille, D. M. Weary, D. J. Sanderson, and J. Rushen. 2007. Softer, higher-friction flooring improves gait of cows with and without sole ulcers. J. Dairy Sci. 90:1235-1242.

Flower, F. C., D. J. Sanderson, and D. M. Weary. 2005. Hoof pathologies influence kinematic measures of dairy cow gait. J. Dairy Sci. 88:3166-3173.

Flower, F. C., and D. M. Weary. 2006. Effect of hoof pathologies on subjective assessments of dairy cow gait. J. Dairy Sci. 89:139-146.

Ito, K., M. A. G. von Keyserlingk, S. J. LeBlanc, and D. M. Weary. 2010. Lying behavior as an indicator of lameness in dairy cows. J. Dairy Sci. 93:3553-3560.

Moreau, M. S., A. Siebert, and E. Schlecht. 2009. Use of a tri-axial accelerometer for automated recording and classification of goats' grazing behaviour. Appl. Anim. Behav. Sci. 119:158-170.

NRC. 2001. Nutrient Requirements of Dairy Cattle. 7th rev. ed. National Academy Press, Washington, DC.

Pastell, M. E., and M. Kujala. 2007. A probabilistic neural network model for lameness detection. J. Dairy Sci. 90:2283-2292.

Pastell, M. E., J. Tiusanen, M. Hakojärvi, and L. Hänninen. 2009. A wireless accelerometer system with wavelet analysis for assessing lameness in cattle. Bios. Eng. 104:545-551.

Phillips, C. J. C. 2002. Cattle Behaviour and Welfare. 2nd ed. Blackwell Science Ltd., Oxford, UK.

R Development Core Team. 2008. R: A Language and Environment for Statistical Computing. R Foundation for Statistical Computing, Vienna, Austria.

Rajkondawar, P. G., M. Liu, R. M. Dyer, N. K. Neerchal, U. Tasch, A. M. Lefcourt, B. Erez, and M. A. Varner. 2006. Comparison of models to identify lame cows based on gait and lesion scores, and limb movement variables. J. Dairy Sci. 89:4267-4275.

Rushen, J., and A. M. de Passillé. 2006. Effects of roughness and compressibility of flooring on cow locomotion. J. Dairy Sci. 89:29652972.

Rushen, J., E. Pombourcq, and A. M. d. Passillé. 2007. Validation of two measures of lameness in dairy cows. Appl. Anim. Behav. Sci. 106:173-177.

SAS Institute. 2003. SAS User's Guide. SAS Institute Inc., Cary, NC.

Tanida, H., Y. Koba, M. Toze, I. Ishii, J. Rushen, and A. M. de Passille. 2008. The effect of hoof trimming on dairy cow gait, assessed by 3-dimensional acceleration sensing. Page 194 in Proc. 15th Symp. 7th Int. Conf. Lameness in Ruminants, Kuopio, Finland. Savonia University of Applied Sciences, Kuopio, Finland.

Telezhenko, E., and C. Bergsten. 2005. Influence of floor type on the locomotion of dairy cows. Appl. Anim. Behav. Sci. 93:183-197.

Whay, H. R., D. C. Main, L. E. Green, and A. J. Webster. 2003. Assessment of the welfare of dairy cattle using animal-based measurements: Direct observations and investigation of farm records. Vet. Rec. 153:197-202. 